\title{
Surgical stabilization of canine lateral scapulohumeral luxation using extracapsular tension suture with screws and nylon wire - case report
}

\author{
Francisco Claudio Dantas Mota ${ }^{1,}$ Mariana Lourenço Veloni ${ }^{1}$, \\ Fernando Dedding Martins ${ }^{1}$, Camila Neves Martins, Aracélle Elisane Alves ${ }^{1}$, \\ Raphael Simões Vieira ${ }^{2}$
}

\begin{abstract}
A dog was consulted with functional disability of the right thoracic limb. Radiographic image showed lateral luxation of the scapulohumeral joint. The animal was submitted to surgical treatment using tension suture with screws and Nylon wire, with satisfactory result and functional use of the limb 30 days postoperatively.

Keywords: Canine, Luxation, Surgery, Trauma.
\end{abstract}

\section{Introduction}

Scapulohumeral joint traumatic luxation is uncommon in dogs (PIERMATTEI et al., 1997) and can occur during the limb movement, when the joint is partially flexed (TALCOTT and VASSEUR, 2003). Traumas generally result in medial humerus head luxation (about $75 \%$ of the cases), but cranial (ENGEN, 1998), caudal (DeANGELIS, 1975) and lateral (CRAIG et al., 1980) are also described, although cranial and caudal luxations are rarely observed (DENNY e BUTTERWORTH, 2006).

Many techniques with variable results have been described for the treatment of shoulder ligament lesion (COOK, 2005). It has been reported

\footnotetext{
1 Veterinary Science Post graduation Program of the Faculty of Veterinary Medicine, Federal University of Uberlândia (UFU)

2 Veterinary Medicine Graduating student - UFU.

* Corresponding author: francisco.mota@ufu.br/ Rua Ceará s/nº Bloco 2T - Campus Umuarama 38400-902 - Uberlândia - MG.

Phone: +55 34 3218-2228
} 
the brachial biceps tendon transposition (KRAMER et al., 2001), the suture stabilization of capsular and ligament (SLOCUM and SLOCUM, 1998) and the scapulohumeral arthrodesis in cases when luxation repair is not viable (PUCHEU and DUHAUTOIS, 2008).

The lateral luxations are observed more frequently in giant breed dogs and are generally caused by traumatic injuries (DENNY and BUTTERWORTH, 2006). The primary apposition of ruptured glenohumeral ligament, if possible, is the chosen technique for the repair. The approach of relapsing shoulder luxation is challenging, with high incidence of luxation recidivism or persistent instability (PUCHEU and DUHATOIS, 2008).

This case report goal is describing the surgical repair of a lateral scapulohumeral luxation with screws and Nylon wire stabilization.

\section{Case report}

A mixed breed dog, 3 years old, $12 \mathrm{Kg}$, was presented to the Veterinary Hospital of Federal University of Uberlândia, because of a functional disability on the right thoracic limb, after a traumatic injury (car accident) that occurred two days prior to the consult.

On physical exam, it was noted that the patient kept his right thoracic limb lifted, the elbow flexed and the distal portion of the limb rotated medially. On palpation, it was detected pain on flexion and extension of the right shoulder, scapulohumeral joint instability, and the humerus greater tubercle was laterally to its normal position.

Radiographic images were done on the scapulohumeral joint (laterolateral and ventrodorsal projections). However, only the ventrodorsal projection with the thoracic limb extended, revealed lateral luxation of the humerus head (Figure 1). After failure on the attempt of luxation closed reduction, the animal was referred to surgery. 

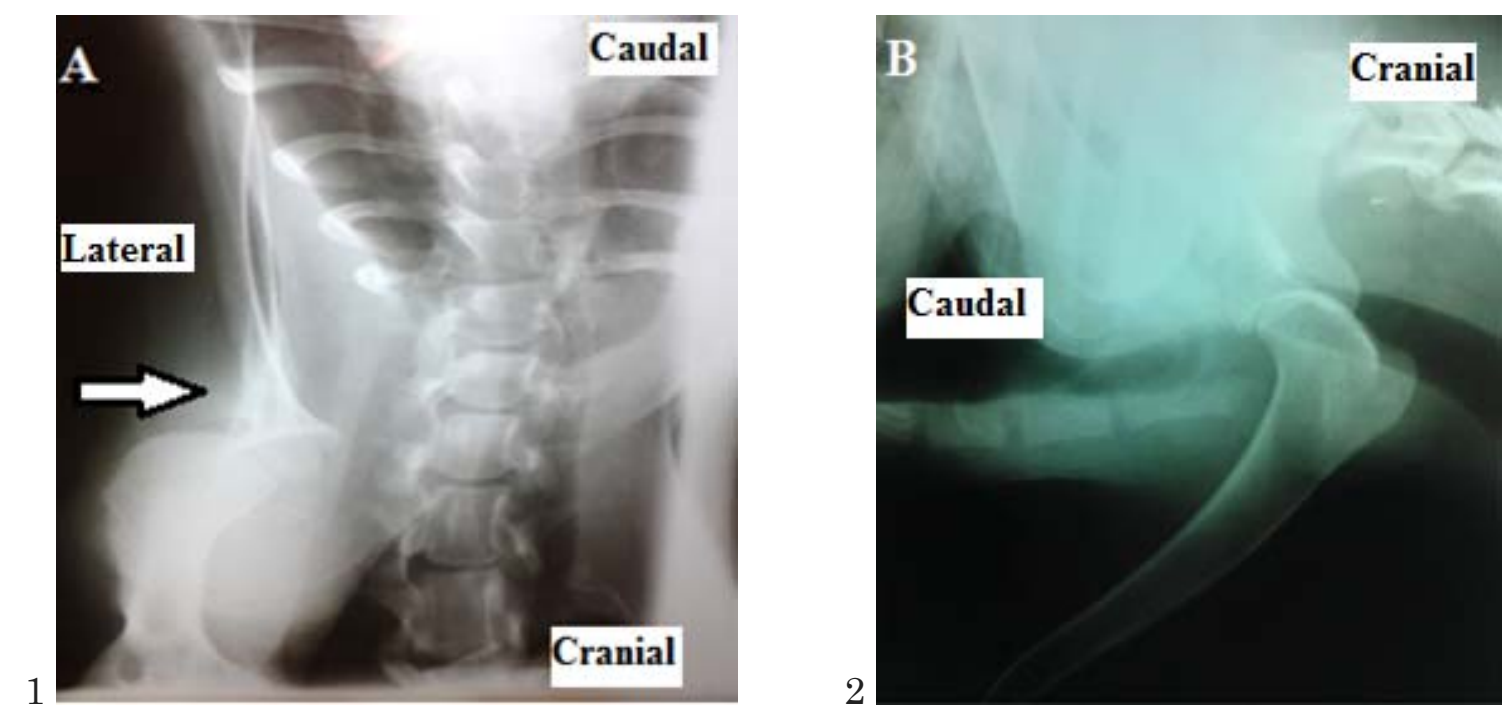

Figure 1: (A) Preoperative radiographic image, ventrodorsal projection, of the scapulohumeral joint with lateral displacement of the humeral head in relation to the glenoid fossa. (B) Preoperative radiographic image of the scapulohumeral joint in laterolateral projection. Uberlândia - MG, 2014.

The surgical access was performed on the craniolateral aspect of the limb, with infraspinatus tenotomy. After the confirmation of the lateral glenohumeral ligament rupture, the reduction of the scapulohumeral luxation was performed. Following the luxation reduction, its stabilization was done with two cortical screws $(2.7 \mathrm{~mm}$ diameter and $16 \mathrm{~mm}$ long) on the lateral scapular neck, one cranial and other caudal to the acromial process. A third screw of same diameter and $20 \mathrm{~mm}$ long was placed next to the humerus lesser tubercle, also laterally (Figure 2A). A number 100 Nylon wire was placed around the screws, in a triangle pattern, resulting on joint stabilization (Figure 2B).

The joint capsule was sutured with simple interrupted pattern and, subsequently, the infraspinatus muscle tendon was sutured applying modified Bunnell-Mayer pattern, using 2-0 Nylon. The other structures were sutured as usual. 

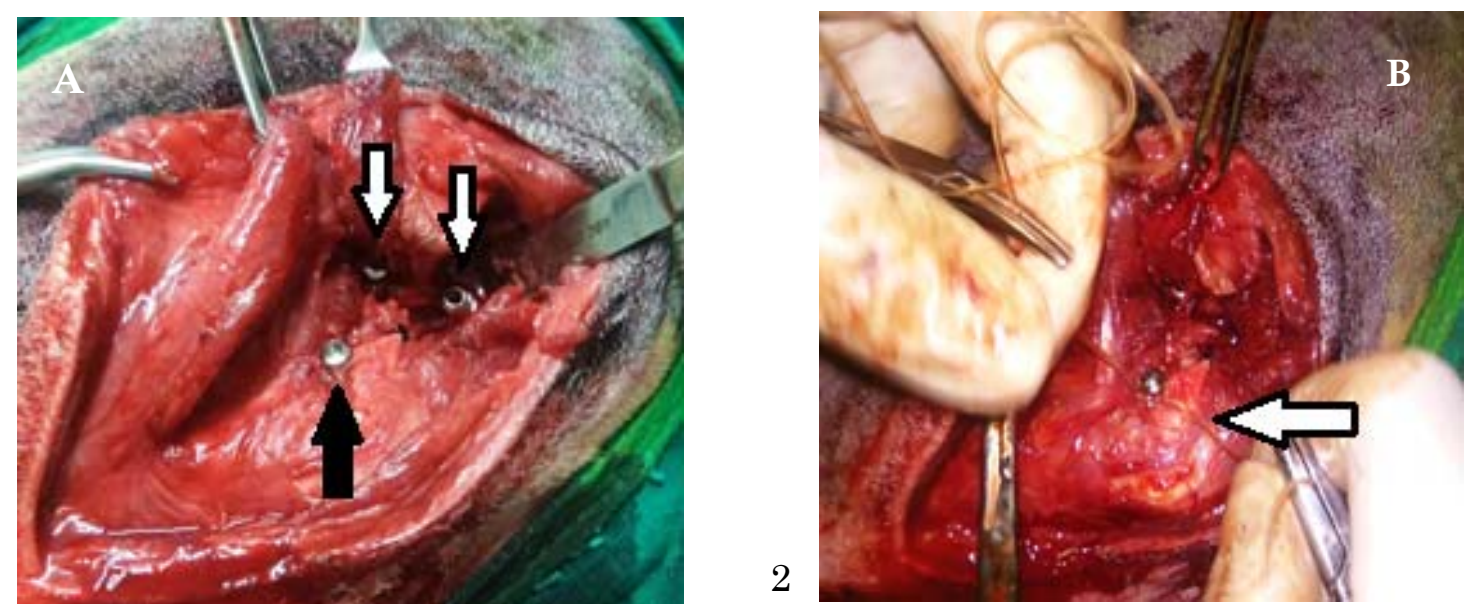

Figure 2. (A) Intraoperative picture of the screws positioned cranial and caudal to the acromial process (white arrows), and a third screw next to the lesser tubercle of the humerus head (black arrow). (B) Screws linked with the nylon wire (arrow), forming a triangle figure. Uberlândia, 2014.

The technique used allowed the stabilization and the congruence repair of the scapulohumeral joint (Figure 3). A spica splint was made and kept for 14 days. In the end of this period, the animal supported his limb with mild lameness, and 30 days postoperatively, the patient presented limb normal functional support.
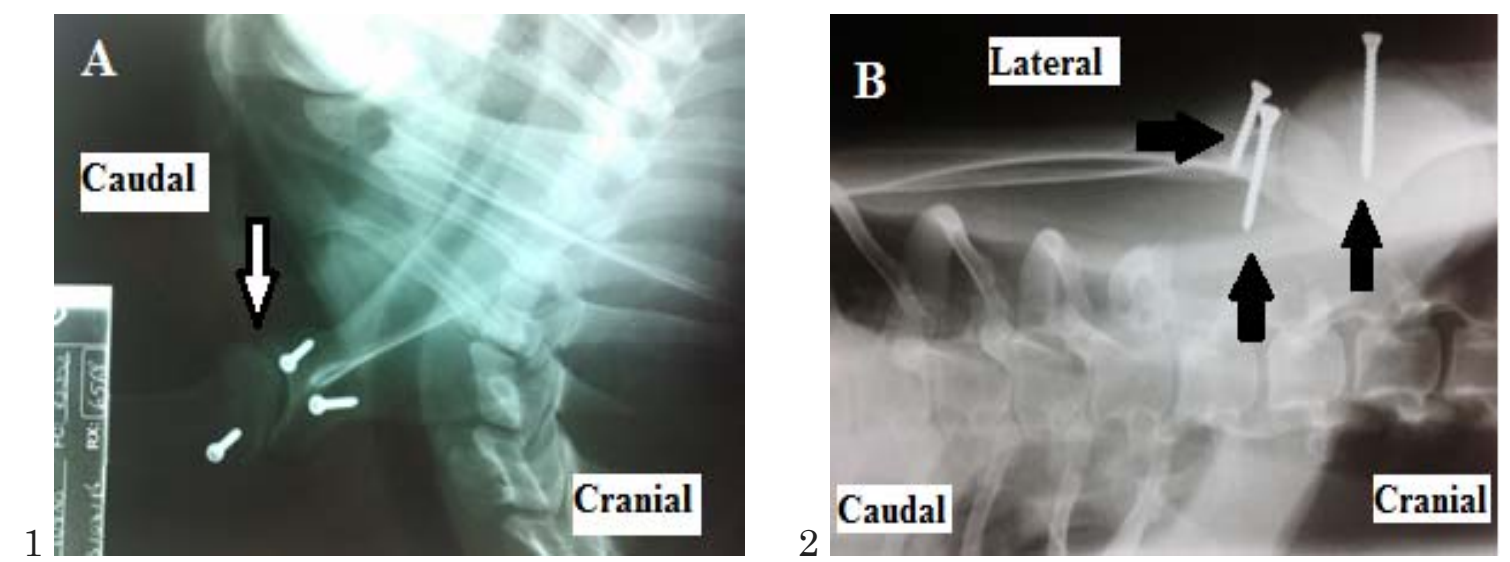

Figure 3. (A) Laterolateral projection radiographic image, showing the perfect congruence of the scapulohumeral joint after the surgical stabilization (white arrow). (B) Ventrodorsal projection showing the screws positioning (black arrows). 


\section{Discussion}

In this case, during the physical exam, the animal kept his right thoracic limb raised with the elbow flexed and adducted laterally, without functionally supporting its limb. This limb positioning was described by Denny and Butterworth (2006) for lateral luxations.

In our case report, the laterolateral radiographic image did not show clearly the real problem with the shoulder joint. According to Fowler et al. (1998), the joint instability measurement is correctly done only on stress radiographies. In this case, only after the ventrodorsal projection, with the animal anesthetised and the limb extended, that was possible to identify the lateral shoulder luxation.

In the present case report, only the lateral glenohumeral ligament was ruptured, and any damage to the infraspinatus tendon was not noted, even it being commonly harmed when there is rupture of the lateral glenohumeral ligament (WATTS et al., 2008 and ROUSSEAU et al., 2010).

In a study aiming to evaluate the scapulohumeral joint stability using canine corpses, Vaseur et al. (1982) cutted in a selective way the tendons next to the joint, as well as the lateral and medial glenohumeral ligaments. The authors observed that the tendons rupture resulted in minimum or no joint instability, however the rupture of the medial or lateral glenohumeral ligaments promoted a significant change on joint movement. This paper corroborates to the observed in this case report, once only the rupture of the lateral glenohumeral ligament resulted on joint instability with following lateral scapulohumeral luxation, even though the other anatomic structures were normal.

Many techniques of shoulder luxation reduction have been described, including the closed reduction that can be complemented using splints, mainly the splint with lateral bandages for 10 to 14 days (DERWIN et al., 2009). The technique of closed reduction used in this case was the same 
described by Fossum (2013), which a pressure was applied to the humerus head with the extended limb, and a lateral pressure applied on the scapula medial surface. However, an immediate luxation relapse was noted.

The open reduction is indicated when after the closed reduction the instability persists, or in cases that the luxation is chronic (JOHSON and DUNNING, 2005). The stabilization of the open reduction can be accurately accomplished by the lateral transposition of the brachial biceps tendon, applying a scapulohumeral resistance bandage (INNES, 2007), and imbrication of the musculature next to the joint (SEMEVOLOS et al., 1998).

Vasseur (1983) described six cases treated with lateral transposition of the brachial biceps tendon, in which five dogs presented normal limb function and one presented occasional lameness. Nowadays, this technique has been widely used in the surgical treatment of joint instability, obtaining success on the joint immediate stabilization (VANDERWEERD et al., 2007). However, it has been noted a congruence loss with time (TOBIAS; JOHNSTON, 2012), leading to degenerative joint disease (SEMEVOLOS et al., 1998). Because of these evidences, the extracapsular suture of lateral tension technique was chosen, considering it ease application and lower invasiveness, and due to the lack of degenerative joint disease reports, probably because there is no positioning change in the anatomical structures, being then successfully used in some species, as swine and alpaca (VANDEERWERD et al., 2007; ROUSSEAU et al., 2010).

Purohit et al. (1985) described only two points for fixation of the tension suture on the stabilization of the lateral scapulohumeral luxation. On the technique described in this case report, it was used three points of fixation to the lateral stress suture, because it allows higher joint rotational stability without impairment of the joint normal movement (ROUSSEAU et al., 2010).

The spica splint was used on the immediate postoperative because, according to Davidson et al. (2005), Velpeau bandage is not recommended in 
cases of canine lateral shoulder luxations considering the occurrence of increased lateral rotation of the humerus head.

Johnson and Dunning (2005) described that a spica splint can be kept in the thoracic limb for 14 days after closed or opened reductions of lateral shoulder luxation, and that exercising must be limited for 4 weeks. The patient here reported was kept with the spica splint for 14 days, presenting normal limb function 30 days postoperatively.

Cook et al. (2005) wrote that, although there is a vast number of techniques for the canine shoulder stabilization, their success is variable, leading to a very challenging and expensive treatment, as long as the luxation relapse or persistent instability have high incidence, even after surgical treatment (PUCHEU and DUHATOIS 2008).

In this report, there was not evidence of luxation relapse, once the animal had its limb function considered normal 30 days after the surgical procedure, without signs of joint degeneration, demonstrating the efficacy of the technique described.

\section{Conclusion}

The surgical technique used in this case report was effective for the treatment of scapulohumeral lateral luxation, maintaining the joint congruence, with an easy execution and no necessity of highly specific surgical instruments, being relatively less invasive than the other techniques reported.

\section{References}

CRAIG, E.; HOHN, R.; ANDERSON, W. Surgical stabilisation of traumatic medial shoulder dislocation. Journal of the American Animal Hospital Association, v.1, p. $93-102,1980$. 
COOK, J.L.; RENFRO, D.C.; TOMLINSON, J.L.; SORENSEN J.E. Measurement of angles of abduction for diagnosis of shoulder instability in dogs using goniometry and digital image analysis. Veterinary Surgery. v.34, p.463-468, 2005.

DAVIDSON, J.R.; KERWIN, S.C.; MILLIS, D.L. Rehabilitation for the orthopedic patient. Veterinary Clinics of North America: Small Animal Practice. v. 35, p. 1357-1388, 2005.

DEANGELIS, M. Luxations of the shoulder joint. In: BOJRAB, M.J (ed). Current techniques in Small Animal Surgery. Philadelphia: Lea and Febiger, 1975, p. 499-504.

DENNY, H.R.; BUTTERWORTH, S.J. Cirurgia Ortopédica em Cães e Gatos. 4 ed. São Paulo: Roca, 2006, p.235-263.

DERWIN, K.A.; CODSI, M.J.; MILKS, R.A.; BAKER, A.R.; MCCARRON, J.A.; IANNOTTI, J.P. Rotator cuff repair augmentation in a canine model with use of a woven poly-l-lactide device. The Journal of bone and joint surgery. v. 91, p. 1159, 2009.

ENGEN, M.H. Surgical treatment of shoulder luxations. In: BOJRAB, M.J (ed). Current Techniques in Small Animal Surgery. Philadelphia: Lea and Febiger 1998, v. 4, p. 1075-1082.

FOSSUM, T.W. Scapulohumeral joint luxation. Small Animal Surgery. St. Louis, Missouri: Elsevier, 2013, p. 1255-1266.

FOWLER, J.D.; PRESNELL, K.R.; HOLMBERG, D.L. Scapulohumeral arthrodesis: results in 7 dogs. Journal of the American Animal Hospital Association. v.24, p.667-672, 1988. 
INNES, J.F. Diagnosis of shoulder lameness in adult dogs. In: NORTH AMERICAN VETERINARY CONFERENCE (NAVC), 2007. Orlando, Flórida, 2007, p.890.

KRAMER, M.; GERWING, M.; SHEPPARD, C.; SCHIMKE, E. Ultrasonography for the diagnosis of diseases of the tendon and tendon sheath of the biceps brachii muscle. Veterinary Surgery. v.30, p.64-71, 2001.

PIERMATTEI, D.; FLO, G.L. The shoulder joint. In: BRINKER, W.O.; PIERMATTEI, D.; FLO, G.L. Handbook of small animal orthopedics and fracture repair. (3.eds). Philadelphia: W. B. Saunders, 1997. p.228-260.

PUCHEU, B.; DUHAUTOIS, B.; Surgical treatment of shoulder instability. A retrospective study on 76 cases (1993-2007). Veterinary Comparative Orthopaedics and Traumatology. v. 21, p.368-374, 2008.

PUROHIT, N.R.; CHOUDHARY, R.J.; CHOUHAN, D.S.; SHARMA, C.K. Surgical repair of scapulohumeral luxation in goats. Modern Veterinary Practice. v. 66, p. 758-759, 1985.

ROUSSEAU, M.; ANDERSON, D.E.; MIESNER, M.D.; SCHULZ, K.L.; WHITEHEAD, C.E. Scapulohumeral joint luxation in alpacas: 10 cases (20032009). Journal of the American Veterinary Medical Association. v. 237, p.1186-1192, 2010.

SEMEVOLOS, S.A.; NIXON, A.J.; GOODRICH, L.R.; DUCHARME, N.G. Shoulder joint luxation in large animals: 14 cases (1976-1997). Journal of the American Veterinary Medical Association. v. 213, p. 1608-1611, 1998.

SLOCUM, B.; SLOCUM, T.D. Suture stabilisation for luxations of the shoulder. In: BOJRAB, M.J. (ed.) Current Techniques in Small Animal Surgery. Philadelphia: Lea and Febiger, 1998, p. 1079-1081. 
TALCOTT, K.W.; VASSEUR, P.B. Luxation of the scapulohumeral joint. In: SLATTER, D. (eds.). Textbook of small surgery, Philadelphia: W.B. Saunders, 2003, p.1902.

TOBIAS, K.; JOHNSTON, S. Veterinary Surgery: Small Animal. 1 ed. St. Louis: Elsevier Saunders, 2012, p.706.

VANDERWEERD, J.M.; CLEGG, P.; WAWA, E. Treatment of recurrent luxation of the shoulder in an alpaca. Veterinary Record. v. 160, p. 304-306, 2007.

VASSEUR, P.B.; MOORE, D.; BROWN, S.A. Stability of the canine shoulder joint: an in vitro analysis. American Journal of Veterinarian Research, v. 43, n. 2, p.352-355, 1982.

VASSEUR, P.B. Clinical results of surgical correction of shoulder luxations in dogs, Journal of the American Animal Hospital Association. v. 182, p. 503, 1983.

WATTS, A.E.; FORTIER, L.A.; NIXON, A.J. A technique for internal fixation of scapulohumeral luxation using scapulohumeral tension sutures in three alpacas and one miniature steer. Veterinary Surgery. v. 37, p. 61-165, 2008. 